\title{
Equality of Resources and Equality of Welfare: A Forced Marriage?
}

\section{Citation}

Scanlon, Thomas M. 1986. Equality of resources and equality of welfare: A forced marriage? Ethics 97, no. 1: 111-118.

\section{Published Version}

http://dx.doi.org/10.1086/292820

\section{Permanent link}

http://nrs.harvard.edu/urn-3:HUL.InstRepos:3311525

\section{Terms of Use}

This article was downloaded from Harvard University's DASH repository, and is made available under the terms and conditions applicable to Other Posted Material, as set forth at http:// nrs.harvard.edu/urn-3:HUL.InstRepos:dash.current.terms-of-use\#LAA

\section{Share Your Story}

The Harvard community has made this article openly available.

Please share how this access benefits you. Submit a story.

Accessibility 


\section{CHICAgo JOURnals}

Equality of Resources and Equality of Welfare: A Forced Marriage?

Author(s): T. M. Scanlon, Jr.

Source: Ethics, Vol. 97, No. 1 (Oct., 1986), pp. 111-118

Published by: The University of Chicago Press

Stable URL: http://www.jstor.org/stable/2381409

Accessed: $17 \overline{/ 07 / 2009 \text { 16:45 }}$

Your use of the JSTOR archive indicates your acceptance of JSTOR's Terms and Conditions of Use, available at http://www.jstor.org/page/info/about/policies/terms.jsp. JSTOR's Terms and Conditions of Use provides, in part, that unless you have obtained prior permission, you may not download an entire issue of a journal or multiple copies of articles, and you may use content in the JSTOR archive only for your personal, non-commercial use.

Please contact the publisher regarding any further use of this work. Publisher contact information may be obtained at http://www.jstor.org/action/showPublisher?publisherCode=ucpress.

Each copy of any part of a JSTOR transmission must contain the same copyright notice that appears on the screen or printed page of such transmission.

JSTOR is a not-for-profit organization founded in 1995 to build trusted digital archives for scholarship. We work with the scholarly community to preserve their work and the materials they rely upon, and to build a common research platform that promotes the discovery and use of these resources. For more information about JSTOR, please contact support@jstor.org. 


\section{Equality of Resources and Equality of Welfare: A Forced Marriage?*}

\section{T. M. Scanlon, Jr.}

There are many points in John Roemer's paper which I would like to discuss. Since I am in general agreement with his criticisms of bargaining theory as an approach to distributive justice, I will focus on the question of equality of welfare versus equality of resources and the striking theorem which Roemer states in the fourth section of his paper. This theorem purports to show that, insofar as it claims to differ from equality of welfare, the idea of equality of resources is incoherent: there are elements within this idea itself which lead inexorably to the conclusion that any acceptable allocation mechanism must be welfare equalizing. In addition, Roemer suggests that his axioms render "the distinction between preferences and resources extremely hazy" (p. 107) and "force upon us a reductionst, determinist program" (p. 109).

Roemer's conclusion is not that we must advocate equality of welfare but, rather, that adequate principles of distributive justice must move beyond "economic environments" and be sensitive to the "names" of goods: they must take into account which goods are being distributed, not merely the level of utility (preference satisfaction) that is produced. I agree with this conclusion, and I imagine that any defender of equality of resources would have agreed from the outset. This leads me to look back at Roemer's axioms with a more critical eye.

In what follows I will argue, first, that the axioms which Roemer puts forward as a characterization of resource egalitarianism in fact include principles which only a welfarist would accept. Second, I will argue that the welfarism which these axioms require is not as extreme as Roemer suggests: they do not "force upon us a reductionist, determinist program" unless all forms of welfarism do so. Finally, in the concluding sections of the paper, I will consider some problems which Roemer's discussion raises for resourcism and discuss the issue of "ideal" versus "second-best" theory.

* This is a much revised version of comments on John Roemer's "The Mismarriage of Bargaining Theory and Distributive Justice" (in this issue), delivered at the Weingart conference in March 1985. I am grateful to Joshua Cohen and John Rawls for helpful comments on an earlier draft.

Ethics 97 (October 1986): 111-118

(C) 1986 by The University of Chicago. All rights reserved. 0014-1704/87/9701-0012\$01.00 


\section{AXIOMS: RESOURCIST OR WELFARIST?}

A natural suspicion is that Roemer's axioms somehow incorporate welfarist intuitions which are not part of the idea of equality of resources but alien to it. Consider, for example, axioms D2, Pareto optimality, and D4, resource monotonicity, both of which employ a utility-based notion of Pareto dominance. Any principle of resource equality requires some means of comparing bundles of resources as "larger," "smaller," or "equal," and it would be question begging to assume at the outset that this standard of comparison must just be the amount of utility which a bundle produces. Employing a resourcist notion of "size," we could formulate resourcebased analogues to D2 and D4. Call these axioms D2r and D4r. Axiom D2r says that a mechanism must not choose an allocation $a$ if there is another, $a^{\prime}$, which assigns some person a "larger" bundle and no one a "smaller" bundle than that assigned by $a$. Axiom $\mathrm{D} 4 \mathrm{r}$ says that when the available resources increase, no one's assigned bundle may become "smaller."

Since the "size" of a resource bundle will depend on which goods it contains, that is, on what Roemer calls the "names" of these goods, this notion cannot even be formulated within the system which Roemer provides. It is excluded by the domain axiom $\mathrm{D} 1$, which requires mechanisms to be defined on economic environments. Nonetheless, D2r and D4r are requirements which any proponent of resource egalitarianism ought to accept. It may be that under plausible assumptions about the idea of resource bundle "size," and given the usual assumptions about utility functions, D2r and D4r imply their utility-based correlates. Nonetheless, D2 and D4 could reasonably be thought to be no part of the idea of equality of resources. A resource egalitarian may believe that "the usual assumptions" about utility do not always hold or, more generally, may reject utility as a standard for measuring distributive shares. The idea that "if the total bundle of resources increases, neither agent's utility falls" (Roemer, p. 105) might be thought to express an optimistic (welfarist) attitude toward the consequences of economic development rather than a necessary tenet of resource egalitarianism.

Consider now Roemer's axiom D5, consistency of resource allocation across dimensions (CONRAD). What is the rationale for including this consistency requirement as part of a characterization of resource egalitarianism? The moral of the Andrea and Bob story is that whenever there are "hidden resources" (such as endorphin levels) which influence individual utility these must be included as part of the resource bundles which are to be equalized. This idea has intuitive force, and I will return to it later. But the effect of CONRAD is much broader. Since CONRAD is formulated in terms of economic environments, it is blind to matters of causal dependence. Suppose that, in some environment $\xi$ involving $m+n$ goods, once $n$ of these goods have been distributed in a certain way the utility consequences of possible distributions of the remaining $m$ goods are exactly the same as the utility consequences of distributions 
of $m$ goods in some other ( $m=$ good) environment $\xi^{*}$. Then CONRAD requires that (assuming the original distribution of $n$ goods is accepted) the remaining $m$ goods in $\xi$ and the $m$ goods in $\xi^{*}$ must be distributed in exactly the same way whether or not these are the same goods and whether or not the $\mathrm{n}$ additional goods are in any sense present as "hidden resources" influencing individual utility levels in the smaller environment.

Note that, given the richness of the domain of economic environments, for any environment $\xi^{*}$ and mechanism $\mathrm{F}$, there will be many "extended" environments $\xi$ related to $\xi^{*}$ in the way just described. Not all of the extra resources in these extended environments will represent "hidden resources" present in societies represented by $\xi^{*}$. Nonetheless, CONRAD requires "consistency" between each of these environments and $\xi^{*}$. Why should this be required? The most natural answer is that utility sums up all relevant reasons for distinguishing between distributions from the point of view of justice; therefore, when the utility consequences of possible distributions in two situations are the same, the same distributions must be selected as just in each case. This rationale fits CONRAD exactly, but it is clearly a welfarist intuition, one which a resource egalitarian is unlikely to accept.

Another rationale for CONRAD, perhaps the one Roemer has in mind, would be this: whenever two environments $\xi^{*}$ and $\xi$ are related in such a way that it is possible that the additional goods in $\xi$ represent "hidden resources" in a society represented by $\xi^{*}$, then the two should be treated in a way that is "consistent." (In this argument, the expressive poverty of the language of economic environments serves as an excuse for what lawyers call "overbreadth.") Does this rationale provide grounds for a resource egalitarian to accept CONRAD? It would do so if the resource egalitarian agreed with the moral of the story of Andrea and Bob as Roemer describes it, and if the resource egalitarian accepted the restrictions of the language of economic environments. These are, however, two fairly large "ifs."

To sum up: because of the limited expressive power of the language of economic environments, the "fit" between CONRAD and an arguably resourcist response to the story of Andrea and Bob is only approximate. Indeed, there is so much slack here that a resourcist who accepts CONRAD as a way of dealing with such examples will have adopted an axiom the most natural rationale for which is a broad welfarist principle which he would hardly accept on its own.

\section{PREFERENCES AS RESOURCES?}

Let me turn now from the rationale for CONRAD to the philosophical implications of adopting it. The effect of CONRAD, Roemer says, is to render "the distinction between preferences and resources extremely hazy" (p. 107). This remark is followed by a discussion of "Fundamental Preferences," and Roemer later observes that "the domain assumption allows us to represent aspects of a person's preferences as if they were 
resources, and the CONRAD axiom enforces a certain consistency between the allocation mechanism's treatment of these two representations of a given world. The domain assumption forces upon us a reductionist, determinist program" (p. 109).

I take it that what Roemer has in mind here is that when two economic environments $\xi=\{m+n ; \overline{\mathrm{x}}, \overline{\mathrm{y}} ; u, v\}$ and $\xi^{*}=\left\{m ; \overline{\mathrm{x}} ; u^{*}, v^{*}\right\}$ are related in the way described in the antecedent of CONRAD, the preferences underlying $u^{*}$ and $v^{*}$ are "represented as if they were resources" because these preferences are seen as resulting from a particular allocation of the resources represented by $\bar{y}$. It is by including, for any $\xi^{*}$, an environment $\xi$ related to it in this way that the domain assumption "forces on us a reductionist, determinist program."

But this involves reading into these axioms a meaning that is not really there. To begin with, the conditions laid down in CONRAD do not insure that $\xi^{*}$ and $\xi$ are two representations of a single "given world." Moreover, in the absence of "names," these conditions tell us very little about the resources involved. Since $\overline{\mathrm{x}}$ is only an $m$-tuple of real numbers until $\xi^{*}$ and $\xi$ are identified with more fully described societies there is no answer to the question whether the resources represented by $\overline{\mathrm{x}}$ in these two environments are the same or different. All that is required by the abstract characterization of $\xi^{*}$ and $\xi$ is that these goods give rise to utility in the same way.

Suppose, however, that we take $\xi^{*}$ and $\xi$ to represent (possibly identical) societies $\mathrm{s}^{*}$ and $\mathrm{s}$ in which the resources measured by $\overline{\mathrm{x}}$ are the same. Call these " $x$ goods" and the additional resources in $s$ " $y$ goods." Even given this assumption, the descriptions of $\xi^{*}$ and $\xi$ taken together with Roemer's axioms commit us to no claim whatever about the relation between $y$ goods and individual preferences over $x$ goods (or about the presence of $y$ goods as hidden resources in $\mathrm{s}^{*}$ ). For all that is said by $\mathrm{D} 1$ and CONRAD, this relation might be any of the following.

1. It might be no relation at all. People in s may have the same preferences for $x$ goods that people in $\mathrm{s}^{*}$ do, but it may be that these preferences would be the same whatever level of $y$ goods the people in s were consuming. (Perhaps $y$ goods have significance only within certain social practices which add "an extra dimension" to life in s but do not interact with other consumption patterns.)

2. It might be a relation like that between my preferences for certain kinds of crackers and the availability of certain kinds of cheese. If people in s enjoy consuming certain $x$ goods only in conjunction with certain $y$ goods, then their preferences for $x$ goods will depend on the amounts of $y$ goods they are consuming. In particular, these preferences will be like those of people in $s^{*}$ only when $y$ goods are being consumed in certain quantities.

3. Finally, it might be like the relation assumed to hold in the story of Andrea and Bob between the utility derived from corn and the presence of endorphins. 
Only the last of these possibilities involves anything like "a reductionist, determinist program." This last interpretation of the relation between $\xi^{*}$ and $\xi$ is consistent with the axioms D1-D6 but is not forced upon us by them since they are equally compatible with the other two interpretations I have described.

What "forces upon us a reductionist, determinist program," if anything does, is the story Roemer tells to motivate the CONRAD axiom. The situation here appears to me to be this. Roemer wants to push a resource egalitarian toward equalizing welfare. To do so, he considers a case in which the preferences of a person with less than equal utility are the result of a particular allocation of "hidden" resources. (The resource egalitarian might be indifferent to Bob's utility level per se, but is supposed to pay attention when it is seen that this results from an allocation of "hidden" resources.) Having used the story of Andrea and Bob to give a resource egalitarian reason to adopt CONRAD, Roemer then reads the circumstances of this example into the interpretation of that axiom. But this is illicit. As I have argued in the previous section, the most natural interpretation of CONRAD (and of the other axioms) is a straightforwardly welfarist one. This interpretation is quite understandably not of interest to Roemer. Given the purposes of his argument, the question which interests him is whether there exists a compelling resourcist rationale for the axioms he needs. But the natural welfarist rationale is there nonetheless. It follows, therefore, that these axioms do not "force upon us a reductionist, determinist program" unless welfarism does so. Perhaps it does, but given the range of possible readings of Roemer's axioms I do not believe that they help to show that this is the case.

\section{WHICH RESOURCES?}

Which goods and conditions should be counted as resources in a resourceegalitarian conception of justice? The pressure toward "determinism" in Roemer's paper arises from the answer to this question which is implicit in his discussion of the example of Andrea and Bob: anything which affects individual utility levels should be counted as a resource (and conditions which do this by altering preferences are no different from goods which do it by satisfying them).

This is an answer which a resourcist might well wish to reject, but some alternative must be provided. It would be arbitrary simply to begin an account of justice with some list of resources taken as given and in need of no defense. A reasonable desire to avoid this kind of arbitrariness, I believe, is what lies behind Roemer's wariness about "names" and his concern that a theory employing them would "impose" values on people who need not share them. No list of resources can be taken as fundamental; any list must be defended with reference to the needs and interests of the people to whom the theory is meant to apply. If we take this to mean that it must be defended with reference to their preferences, then it seems to follow that any theory of justice must, at base, be welfarist. If we add 
the observation that welfare-that is, utility-can be increased by resources which modify preferences as well as by those which satisfy them, then we seem to have opened the door to "treating preferences like resources" and hence, at least potentially, to what Roemer called "a determinist program." But these conclusions would be premature.

The question at issue is the selection of a standard for measuring distributive shares, where this standard is to be used by people with differing and malleable tastes and pręferences. This fact of differing preference is part of our reason for being concerned about the threat of "arbitrary" or "imposed" standards. One response to this fact is to look for some common ground behind our disagreement: we may have different preferences, but we are all concerned to have these preferences satisfied to the greatest possible degree-that is, concerned with our own utility. A second approach is to look for common elements in what we prefer: we share general interests in having food, shelter, opportunities for education, and so on. A list of resources is a fair standard according to this approach if it adequately measures people's ability to advance these general categories of shared interests.

Resources which advance these interests may thereby "increase utility." But a resourcist conception of justice need not regard the importance of these interests as subsumed within that of a larger whole, utility. The reasons against doing so are particularly clear in the case of resources such as education, which contribute to preference change. People want to have preferences be ones which stand up in the light of reflection and the available facts. But they do not view preferences as things which they have reason to change whenever this would yield greater utility. A justification of preference-changing resources which appeals to shared general interests is thus more consistent with the view people take of their own preferences than a welfarist justification would be.

Consider another example. Assume we live in a society marked by sharp differences in religious belief. Aware of these differences, we can also recognize "the opportunity to pursue one's religious convictions" as a shared general interest in the sense just discussed. Appealing to this interest, one can then argue for the importance of certain resources: protection against discrimination, opportunities for religious observance, freedom to read, and disseminate literature on religious topics, and so on. If these resources are fairly distributed, however, that is all that a resourcist view of justice requires as far as religion is concerned. The choice of religion (or no religion) is entirely up to each person, and the amount of utility resulting from this choice is specifically not an object of public policy.

Consider an alternative. What religion a particular person belongs to is a contingent matter: I might have grown up in circumstances in which it would never have occurred to me to be a Catholic (or never occurred to me not to be one). Such differences in religious belief are one thing that can produce differences in utility level, and someone who 
regarded equality of welfare as the standard of interpersonal justification would have to regard these differences as being grounds for compensation: compensation for having acquired a particularly onerous or guilt-inducing religion or one particularly unsuited to one's own personal strengths and weaknesses. This strikes me as distinctly odd. Quite apart from the fact that it might destroy the point of religious burdens to have them lightened by social compensation, the idea that these burdens are grounds for such compensation (a form of bad luck) is incompatible with regarding them as matters of belief and conviction which one values and adheres to because one thinks them right.

I have suggested that argument about justice employs "names" of specific resources and that these are justified with reference to "names" of shared general interests. I have argued that the use of such a standard of distributive shares is not arbitrary and that it is more compatible with the view people take of their own preferences and interests than a notion of utility would be. A list of "shared general interests" is, of course, not simply given; it is something whose fairness in a particular situation has to be argued for. This argument, in turn, does not reach "beyond names," but involves mentioning specific further interests and arguing that they are insufficiently recognized by the currently accepted way of measuring bundles of resources. In this respect, argument about justice involves names "all the way down."

Another way of putting the point would be to say that "preference" is itself a "name," and not a particularly potent one. Simply to say "But I would strongly prefer ..." is not yet a very strong argument for revising the list of resources. It is only when the interest at stake is given a more informative "name" that we can see what would be involved in recognizing it as having special force as a claim of justice.

\section{IDEAL THEORY?}

At the end of his paper, Roemer remarks, "My concern here has not been with institutions which will implement the just allocation, in which case incentive problems would have to be considered, but simply with what allocation is desirable. This is first-best normative analysis. Before one begins to compromise, it would be nice to know what the goal would be, if everyone knew everything" (p. 110).

I believe, on the contrary, that the terms in which it is appropriate to argue about justice inevitably reflect "nonideal" features of our world, such as our lack of full knowledgé and the kinds of agreement, disagreement, and conflict which are common among us. In particular, it seems to me that institutions are not a matter of "compromise" but have a fundamental place in determining which outcomes are just. There are many reasons for holding institutions to be prior in this way. Here I will mention only one, a reason which is strengthened by the conclusions which Roemer reaches elsewhere in his paper. 
If one believes, as Roemer suggests, that a person's preferences are largely shaped by outside factors, presumably in particular by social institutions, then the choice of such institutions takes on special importance. What one wants is to have institutions which provide a favorable environment in which to develop preferences and make choices in pursuit of the goals one has adopted: a favorable environment in which to develop and live as a "self-steering mechanism" among other such individuals. We do not have a complete view of what counts as a "favorable environment" of this kind, but we do have a partial account given by a list of the kinds of "resources" it is important to have and the kind of dangers it is important to avoid. As I have indicated above, moral and political argument is a continuing process of debate about these lists. Beyond this, there is no characterization of "the ideal" from which political argument could begin. What each of us, personally, regards as the ideal depends on how we develop within the institutions in which we are placed and is therefore, at any given time, incompletely determined. This openness of possibilities-the idea that what we do and what we value remains to be determined by how we react to and reflect upon our environmentis the freedom which remains to us even as "determined" beings. Moral argument, then, even among such beings, cannot begin from an answer to the question of what would be ideal for us individually and collectively and proceed from there to ask what institutions would realize that ideal. All we can ask of one another is a favorable environment in which to work out and pursue our own differing and as yet incompletely defined conceptions of "the ideal." 